\title{
Serious Obstetrical Complications Admitted in an Intensive Care Unit in Benin
}

\author{
Aboubakar Moufalilou*, Akodjenou Joseph, Tognifode Véronique Medesse, Dangbemey Patrice, \\ Zounma Mawuwè Caleb, Tonato-Bagnan Angeline, Zoumenou Eugene
}

Faculty of Health Sciences, University of Abomey-Calavi, Cotonou, Benin

Email address:

moufaliloua@yahoo.fr (A. Moufalilou)

${ }^{*}$ Corresponding author

\section{To cite this article:}

Aboubakar Moufalilou, Akodjenou Joseph, Tognifode Véronique Medesse, Dangbemey Patrice, Zounma Mawuwè Caleb, Tonato-Bagnan Angeline, Zoumenou Eugene. Serious Obstetrical Complications Admitted in an Intensive Care Unit in Benin. Journal of Gynecology and Obstetrics. Vol. 9, No. 5, 2021, pp. 150-154. doi: 10.11648/j.jgo.20210905.13

Received: August 24, 2021; Accepted: September 8, 2021; Published: September 23, 2021

\begin{abstract}
Introduction: Most complications in pregnancy, delivery or post natal period are managed by obstetricians. However, some are admitted to intensive care units (ICU), for ressucitation. The aim of this study was to describe the epidemiological and clinical profils of patients admitted in the intensive care unit for serious obstetrical complications at the University Associated Hospital of Mother and Child (CHU-MEL). Materials and Methods: This was a descriptive crosssectional study with prospective data collection from October 1 to from October 1 to December 31, 2019. Were included pregnant and women delivered and within 42 days of the postpartum period admitted to the intensive unit care and presenting one of the criteria of severe maternal morbidity as defined by the EPIMOMS study. The analysis of the data was done with the STATA software. Results: The proportion of admissions to the intensive care unit was $15.44 \%$. The patients were young (mean age 27 years), educated $(76.19 \%)$, primigravida $(39.05 \%)$, primiparous $(38.1 \%)$ and without any particular history $(85.71 \%)$. Most of them were referred from the peripheral health centers. The main reasons were complications of hypertension during pregnancy $(53.33 \%)$, bleeding complications $(42.86 \%)$ and infectious complications $(7.62 \%)$. The most used products were antibiotics (92.38\%), analgesics (89.52\%), uterotonics (82.66\%), anticoagulants $(75.24 \%)$, magnesium sulfate $(51.43 \%)$. Conclusion: Serious obstetrical complications are frequent. Their management needs an ICU well equipped especially in reference hospital. It is important that the references respect the norms to avoid that the patients arrive in a critical state.
\end{abstract}

Keywords: Serious Obstetrical Complication, Intensive Unit Care, Benin

\section{Introduction}

Approximately 830 women die every day worldwide due to complications of pregnancy or childbirth [1]. Others complications, which existed before pregnancy, become more serious during pregnancy, especially if they are not managed as part of care [2].

Most of these complications are managed by obstetricians. However, others are admitted to intensive care units.

In China, in 2010, obstetric patients accounted for $0.65 \%$ of all ICU admissions and $0.13 \%$ of all deliveries [3]. In Nigeria, in 2016, there were 101 admissions of obstetric patients for 11,308 births over a two-year period [4]. In Benin, a cross-sectional study with retrospective data collection conducted in the intensive care unit of the University Hospital of Parakou found a frequency of $2.75 \%$ of all admissions [5].

The most common reasons for admission to intensive care units found in various studies are complications of hypertension associated with pregnancy; obstetric haemorrhage and infections [4, 6, 7].

The objective of this work is to study the profile of women presenting a serious obstetrical complication (or severe maternal morbidity) admitted in the intensive care unit of the University Associated Hospital of Mother and Child (CHU-MEL) in Benin.

\section{Materials and Methods}

This is a descriptive cross-sectional study with prospective data collection from 1 October to 31 December 2019. The 
study population consisted of all patients admitted to the obstetrical intensive care unit of CHU-MEL of Cotonou during the study period. Were included pregnant women and women who delivered and withing 42 days postpartum admitted to the intensive care unit of the CHU-MEL and presenting one of the criteria of severe maternal morbidity as defined by the EPIMOMS study. A non-probabilistic method was used. The recruitment was exhaustive. The dependent variables was the serious obstetrical complication. The independent variables were sociodemographic, clinical, and paraclinical. Data were collected by clinical examination of the patients and from medical records, operative reports, and emergency registers using a survey sheet prepared with the kobo collect v1.23.3k tool.

The data analysis was done with the STATA software.

\section{Results}

\subsection{Prevalence}

During the study period 680 patients were admitted to the intensive care unit.

Among them, 105 admissions has been recorded for serious obstetrical complications, i.e. $15.44 \%$ of all admissions to the intensive care unit.

\subsection{Socio-demographic Characteristics}

\subsubsection{Age}

The average age was $27.105 \pm 7.127$. The youngest was 14 years and the oldest 43 years. The median age was 27 years. The majority of the women were under 25 years of age (81.9\%).

Table 1. Distribution of patients by age group.

\begin{tabular}{lll}
\hline & Number percentage & $\mathbf{\%}$ \\
\hline$\leq 24$ years & 40 & 38.1 \\
25-34 years & 46 & 43.8 \\
$\geq 35$ years & 19 & 18.1 \\
Total & 105 & 100 \\
\hline
\end{tabular}

\subsubsection{Educational Level}

Most of the patients were educated $(76.19 \%)$ and those with at least secondary school level represented $47.62 \%$ of all admissions.

\subsection{Mode of Admission}

Most patients were referred (80.95\%). The time between referral and admission to CHU-MEL was more than 60 minutes in $78.82 \%$ of cases. The shortest delay was 17 minutes and the longest was 2880 minutes ( 2 days). The median delay was 125 minutes.

\subsection{Medical Past History}

Among the patients, $14.29 \%$ had a medical history, namely sickle cell disease (6.68\%) and hypertension (4.76\%).

Primigravida and paucigravida represented $67.62 \%$ of all women admitted, nulliparous, primiparous and pauciparous represented $79.05 \%$ of patients.

\subsection{Gravido-Puerperal Status on Admission}

Complications occurred mostly in women outside of pregnancy $(89.52 \%)$ either during post natal period $(67.19 \%)$ or post abortum (13.33\%)

\subsection{Age of Pregnancy}

For the pregnant women, the majority $(52.81 \%)$ were not at term. The average age of the pregnancy was 34.24 weeks \pm 5.41 weeks.

More than half of the patients had attended at least four prenatal consultations.

\subsection{Clinical and Paraclinical Characteristics}

\subsubsection{Clinical Signs on Admission}

The most frequent signs were haemodynamic (paleness for $63.81 \%$, or hypertension $55.24 \%$ ) followed by respiratory distress.

Table 2. Distribution of patients according to clinical signs on admission.

\begin{tabular}{lll}
\hline & Number percentage & \% \\
\hline Respiratory Distress & 22 & 20.95 \\
shock & 10 & 9.52 \\
Paleness & 67 & 63.81 \\
Haemorrhage & 11 & 10.48 \\
Hypertension & 58 & 55.24 \\
Convulsions & 14 & 13.33 \\
Coma with Glasgow score $\leq 8$ & 6 & 5.71 \\
Hyperthermia & 15 & 14.29 \\
Hypothermia & 5 & 4.76 \\
Jaundice & 8 & 7.62 \\
Protéinuria $\geq 3+$ & 41 & 39.05 \\
\hline
\end{tabular}

\subsubsection{Biological Abnormalities Found}

The disorders were predominantly on the blood count (CBC). These were hyperleukytosis $(58.1 \%)$, severe anaemia $(33.33 \%)$ and thrombocytopenia $(24.76 \%)$.

Table 3. Distribution of patients according to biological abnormalities.

\begin{tabular}{lll}
\hline & Effectif & \% \\
\hline Thrombopénia & 26 & 24.76 \\
Aspartate Amino Transférase elevated & 18 & 17.14 \\
Alanine Amino Transférase elevated & 9 & 8.57 \\
Serum creatinine elavated & 11 & 10.48 \\
Severe Anemia & 35 & 33.33 \\
Hyperleucocytosis & 61 & 58.1 \\
Hyponatremia & 2 & 1.9 \\
Hypernatrémie & 3 & 2.86 \\
Hypokaliemia & 2 & 1.9 \\
Hyperkaliemia & 8 & 7.62 \\
Total Bilirubinemia elevated & 2 & 1.9 \\
Indirect Bilirubinemia elevated & 2 & 1.9 \\
\hline
\end{tabular}

\subsection{Diagnosis on Admission}

Complications of hypertension in pregnancy were found in $53.33 \%$ of the patients, haemorrhagic complications in $42.86 \%$ and infectious complications in $7.62 \%$ of the women. 
Table 4. Distribution of patients according to diagnosis on admission to the intensive care unit.

\begin{tabular}{lll}
\hline & Number percentage & $\mathbf{\%}$ \\
\hline hypertensive omplications 53,33 & & \\
Eclampsia & 29 & 27.62 \\
Severe Pre-éclampsia & 26 & 24.76 \\
HELLP Syndrome & 1 & 0.95 \\
bleedding complications 48,57 & & \\
post-partum haemorrahage & 16 & 15.24 \\
Abruptio placenta & 12 & 11.43 \\
Prævia placenta & 10 & 9.52 \\
Ectopic pregnancy & 9 & 8.57 \\
Uterine Rupture & 1 & 0.95 \\
post-abortum Haemorrhage & 3 & 2.86 \\
infectious complications 7,61 & & \\
post-abortum Pelvipéritonitis & 2 & 1.9 \\
Sepsis & 1 & 0.95 \\
Severe Malaria & 5 & 4.76 \\
Other complications 14,93 & & \\
Vaso-Occlusive crisis & 2 & 1.9 \\
Severe Anemia & 4 & 3.82 \\
Respiratory Distress & 5 & 4.76 \\
Peripartum Cardiomyopathy & 1 & 0.95 \\
Coma & 1 & 0.95 \\
Severe Thrombopénia & 1 & 0.95 \\
Acute pulmonary oedema & 1 & 0.95 \\
Acute asthma & 1 & 0.95 \\
\hline
\end{tabular}

\subsection{Retained Signs of Severity}

Some patients had several severity criteria as showed in Table 5.

Table 5. Distribution of patients according to the severity criteria selected.

\begin{tabular}{lll}
\hline & Number & $\%$ \\
\hline Acute severe anemia $<7 \mathrm{~g} / \mathrm{dL}$ & 35 & 33.33 \\
Convulsion & 29 & 27.62 \\
post-partum haemorrhage $\geq 1500 \mathrm{~mL}$ & 16 & 15.24 \\
shock & 13 & 12.38 \\
Creatininemia $>15 \mathrm{mg} / \mathrm{L}$ & 10 & 9.52 \\
Acute hypoxemia with SpO2 $\leq 90 \%$ & 8 & 7.62 \\
acute pulmonary oedema & 7 & 6.67 \\
Coma & 6 & 5.71 \\
Blood Transfusion $\geq 4$ packs of red blood & 4 & 3.81 \\
cells & 3 & 2.86 \\
Thrombopenia $<50000 / \mathrm{mm} 3$ & 2 & 1.9 \\
Hystérectomy peripartum & 2 & 1.9 \\
Direct Bilirubinemia $>7 \mathrm{mg} / \mathrm{L}$ & 1 & 0.95 \\
Acute psychiatric disorders & 1 & 0.95 \\
Troponinemia $>1 \mu \mathrm{g} / \mathrm{L}$ & & \\
\hline
\end{tabular}

\section{Discussion}

\subsection{Prevalence}

In this study, the prevalence of serious obstetric complications admitted to the intensive care unit was $15.44 \%$. It is comparable to that found by Traore and al. in Mali in 2012 , i.e. $16.11 \%$. Tchaou and al. in 2013 at the regional university associated hospital of Borgou found a prevalence of $2.75 \%$ [5]. However, that study was conducted in a multipurpose intensive care unit receiving patients from specialties other than gynaecology and obstetrics.

In addition, during the study, a rate of 83.46 complications per 1000 live births has been recorded. This rate is similar to that of Gebrehiwot and al. in Ethiopia in 2014 (85.14 per 1000 live births) and close to that obtained by Kiruja et al in Somalia in 2017 (101.84 per 1000 live births) [8, 9]. However, this rate is higher than those obtained by Ali and al. in 2011 in Sudan (26.45 per 1000 live births) and Bashour and al in 2015 in Egypt $[10,11]$.

This difference could be explained by the inclusion criteria used. Indeed, for patients admitted in the postpartum period, Bashour and al included women who did not make more than 7 days while the current study went up to 42 days after delivery. As for Ali and al, they used the inclusion criteria of Filippi 2005 which have fewer inclusion criteria [12].

\subsection{Socio-demographic Characteristics}

The pregnant women in this series were young with a mean age of $27.11 \pm 7.13$ and were mostly educated. This average is similar to that obtained by Bashour and al (27.8 years) and Gebrehiwot and al. (27.4 years) $[8,11]$. This age corresponds to the period of maximum fertility as described by many authors around the world [13-15]. Tchaou and al in Parakou in 2013 found a lower average age (24.7 years) [5].

\subsection{Mode of Admission and Medical Transport of Patients}

In the current study, $80.95 \%$ of patients admitted to the intensive care unit were referred from peripheral health centers. This very high referral rate is explained by the status of the referral hospital of CHU-MEL. As such, it receives patients with serious pathologies from all health facilities. This situation is observed in most developing countries [16]. According to Supratiko, these referred women are at greater risk than those who came on their own to hospital [17].

This frequency is close to those of Litorp andal in 2014 in Tanzania and Liyew and al in Ethiopia in 2016 who found a rate of $87 \%$ and $88.2 \%$ respectively $[18,19]$.

The transport of patients to referral hospital is very poorly medicalised in this study. Indeed, only $12.94 \%$ of referred patients benefited from medical evacuation compared to $76.1 \%$ found by Liyew andal [18]. Medicalisation remains a major problem due to the lack of human and material resources: absence of ambulance or ambulance without any resuscitation equipment, absence of human resources to accompany the patients. Thus it is not uncommon for patients in vital distress or with a serious pathology (uterine rupture, eclampsia, etc.) to be referred on a motorbike taxi, sometimes without a venous catether, without a referral form or with an incomplete referral form.

\subsection{Clinical Characteristics of the Patients}

The diagnoses on admission were dominated by hypertensive complications (53.3\%) and bleeding complications (48.57\%). Infectious complications accounted for only about $7.2 \%$. Kiruja and al, Liyew and al also found the same pathologies in the same order with respectively $55 \%$ and $53 \%$ for hypertensive complications and $36.7 \%$ and $38 \%$ for bleeding complications $[9,18]$. For Tchaou and al, infectious 
complications were the most common $(79.70 \%)$ followed by hypertensive complications (13.10\%) and haemorrhagic complications $(7.2 \%)$ [5].

\subsection{Past History}

The majority of patients were primigravida or paucigravida $(67.62 \%)$ and primiparous or pauciparous $(79.05 \%)$. This result is close to those found in the literature $[7,5,20,21]$.

\subsection{Period of Admission}

Most of the patients were admitted during postnatal period (76.19\%). Tchaou and al (56.5\%), also made the same observation [5]. This reflects the lack or inadequacy of screening of warning signs by health workers during pregnancy and their ignorance by pregnant women. This can also be explained by the fact that resuscitation anaesthetists admit and manage patients all the more easily when they are no longer carrying the product of conception. Obstetricians then tend to deliver the patients, especially once the fetus has reached pulmonary maturity before handing over.

\subsection{Comorbidities Before Pregnncy}

The comorbidities most frequently encountered in this study were sickle cell disease $(6.67 \%)$ and chronic arterial hypertension (4.76\%). In Parakou, Tchaou and al found in 2012 , in order of frequency, HIV infection $(8.7 \%)$ and sickle cell disease $(2.9 \%)$ [5].

\subsection{Pregnancy Follow-up}

Of these women admitted to ICU, 84.76\% had had at least one prenatal consultation. Litorp and al. and Etoundi and al. also found that the majority of women had attended at least one antenatal consultation (respectively $88 \%$ and $51.4 \%$ ) [19, 22]. On the other hand, Tchaou et al. found $72.4 \%$ [10] of patients who had never attended an antenatal consultation. This could be linked to the better schooling rate of women and better geographical accessibility to health facilities in the southern region compared to the northern region.

Antenatal care coverage varies according to certain sociodemographic characteristics, including the level of education and the household's standard of living. Educated women are more aware of the importance of prenatal consultations [23].

\subsection{Clinical Signs and Biological Abnormalities in the ICU}

The main danger signs found were respiratory distress, circulatory distress and neurological distress. Tchaou and al. in 2013 found quite the same clinical picture in their patients.

Biologically, the most frequent sign of severity was severe anaemia with a haemoglobin level below $7 \mathrm{~g} / \mathrm{dL}$ (33.33\% of patients). Tchaou and al. made the same finding but in a lower proportion $(8.1 \%)$ [5] This relatively low proportion could be explained by the study population chosen. Indeed, Tchaou and al. included in their study all women admitted to intensive care.

\section{Limitations}

We conducted a study limited in an ICU of an hospital. The study has some limitations, notably:

1. The duration of the data collection. Indeed, it lasted three (3) months and two (2) weeks. This is a relatively short period.

2. The patients did not always have the means to pay for the check-up and all the prescribed medication.

\section{Conclusion}

Serious obstetrical complications are frequent and represent $15.44 \%$ of all admissions to the intensive care unit. Their management needs an ICU well equipped especially in reference hospital. Forther more it is important that the references respect the norms to avoid that the patients arrive in a critical state.

\section{References}

[1] Briozzo L, Ponce de León G, Tomasso G, Faúndes A. Overall and abortion-related maternal mortality rates in Uruguay over the last 25 years and their association with policies and actions to protect women's rights. IJGO. 2016; 134: S20-S23201.

[2] Say L, Chou D, Gemmill A, Tunçalp Ö, Moller A-B, Daniels $\mathrm{J}$, et al. Global causes of maternal death: a WHO systematic analysis. Lancet Glob Health. 2014; 2 (6): e323-33.

[3] Leung NY, Lau AC, Chan KK, Yan W. Patients admitted to the Intensive Care Unit: a 10-year retrospective review. Hong Kong Med J. 2010; 16: 18-25.

[4] Igbaruma S, Olagbuji B, Aderoba A, Kubeyinje W, Ande B, Imarengiaye C. Severe maternal morbidity in a general intensive care unit in Nigeria: clinical profiles and outcomes. Int J Obstet Anesth. 2016; 28: 39-44.

[5] Tchaou BA, Tshabu-Aguèmon C, Hounkponou FM, Brouh Y, Aguémon AR, Chobli M. Severe obstetrical morbidities in intensive care at the university hospital of Parakou in Benin: 69 cases. Rev D'Anesthesiology Emergency Medicine. 2013; 18 (3): 9.

[6] Wanderer JP, Leffert LR, Mhyre JM, Kuklina EV, Callaghan WM, Bateman BT. Epidemiology of Obstetric-Related Intensive Care Unit Admissions in Maryland: 1999-2008. Crit Care Med. 2013; 41 (8): 1844-52.

[7] Lelong E, Pourrat O, Pinsard M, Goudet V, Badin J, Mimoz O, et al. Intensive care unit admissions of women during pregnancy or post partum: circumstances and prognosis. A retrospective series of 96 cases. Rev Internal Medicine. 2013; 34 (3): 141-7.

[8] Gebrehiwot Y, Tewolde BT. Improving maternity care in Ethiopia through facility based review of maternal deaths and near misses. Int J Gynecol Obstet. 2014; 127: S29-34.

[9] Maternal near-miss and death incidences - Frequencies, causes and the referral chain in Somaliland: A pilot study using the WHO near-miss approach. Sex Reprod Health. 2017; 12: 30-6. 
[10] Ali AA, Khojali A, Okud A, Adam GK, Adam I. Maternal near-miss in a rural hospital in Sudan. BMC Pregnancy Childbirth. 2011; 11 (1): 48

[11] Bashour H, Saad-Haddad G, dejong J, Ramadan MC, Hassan $\mathrm{S}$, Breebaart $\mathrm{M}$, et al. A cross sectional study of maternal 'near-miss' cases in major public hospitals in Egypt, Lebanon, Palestine and Syria. BMC Pregnancy Childbirth. 2015; 15 (1): 296.

[12] Filippi V, Ronsmans C, Gohou V, Goufodji S, Lardi M, Sahel $\mathrm{A}$, and al. Maternity wards or obstetric emergency rooms? Incidence of near misses in African hospitals. Acta Obstet Gynecol Scand. 2005; 84 (1): 11-6.

[13] Penfold F, Harrison E, Bell J, et Fitzmaurice. A Evaluation of delivery fee exemption policy in Ghana: population estimates of changes in delivery service utilisation in two regions. Ghana medical journal 2007; 41 (3): 100-9.

[14] Traoré B, Kokaina C, Beye SA, Traoré M, Dolo A. Caesarean section at the Segou hospital in Mali. Médecine d'Afrique No. 5711. November 2010. P 513-518.

[15] Jean Dupont Kemfang Ngowa, anny ngassam, jovanny tsuala fouogue, junie metogo, alexis medou, jean marie kasia. Early maternal complications of cesarean section: about 460 cases in two university hospitals in Yaoundé, Cameroon. Pan African Medical Journal. 2015; 21: 265 doi: 10.11604/pamj.2015.21.265.6967.

[16] Ouédraogo CM, Ouédraogo A, Ouattara A, Lankoandé J. The practice of caesarean section in a district hospital in Ouagadougou. Epidemiological, clinical and prognostic aspects, about 3381 cases. Tropical Medicine and Health. Burkina Faso 2015; 25: 194-9.
[17] Gunawan Supratiko, Meg E. Wirth, Endang Achadi, Surekha Cohen, \& Carine Ronsmans, A district-based audit of the causes and circumstances of maternal deaths in South Kalimantan, Indonesia. Bull World Health Organ 2002, 80 (3): 228-234.

[18] Liyew EF, Yalew AW, Afework MF, Essén B. Incidence and causes of maternal near misses in selected hospitals in Addis Ababa, Ethiopia. PLOS ONE 2017; 12 (6): e0179013.

[19] Litorp H, Kidanto HL, Rööst M, Abeid M, Nyström L, Essén B. Maternal near-miss and death and their association with cesarean section complications: a cross-sectional study at a university hospital and a regional hospital in Tanzania. BMC Pregnancy Childbirth. 2014; 14 (1): 244.

[20] Adeoye IA, Onayade AA, Fatusi AO. Incidence, Determinants and perinatal outcomes of near-miss maternal morbidity in IleIfe, Nigeria: a prospective case control study. BMC Pregnancy Childbirth. 2013; 13 (1): 93.

[21] Nakimuli A, Nakubulwa S, Kakaire O, Osinde MO, Mbalinda SN, Kakande N, et al. The burden of maternal morbidity and mortality attributable to hypertensive disorders in pregnancy: a prospective cohort study from Uganda. BMC Pregnancy Childbirth. 2016; 16: 205.

[22] Etoundi O, Mbengono M, Tchokam L, Danwang C, Kago Tcheyanou L, Afane E, et al. Obstetric complications admitted to the ICU: Epidemiology, Diagnosis, and Prognosis. Health Sci Dis. 2017; 18 (1).

[23] National Institute of Statistics and Economic Analysis (INSAE) and ICF. 2019. Benin Demographic and Health Survey, 20172018. Cotonou, Benin and Rockville, Maryland, USA: INSAE and ICF. 